\title{
A HETEROGENEIDADE DOS DISCURSOS EM SAÚDE REPRODUTIVA E MEIO AMBIENTE PRESENTES NA MÍDIA IMPRESSA
}

\section{THE HETEROGENEITY OF DISCOURSE IN REPRODUCTIVE HEALTH AND ENVIRONMENT AT PRINTED MEDIA}

\author{
Maria Angélica Costa ${ }^{1}$, Sergio Nesi da Fonseca ${ }^{2}$, Ivone Evangelista Cabral $^{3}$ \\ ${ }^{1}$ EAD/ENSP/FIOCRUZ e Núcleo de Tecnologia Educacional em Saúde/UFRJ \\ ${ }^{2}$ Fundação Getúlio Vargas \\ ${ }^{3}$ Escola de Enfermagem Anna Nery/UFRJ e Núcleo de Tecnologia Educacional em Saúde/UFRJ
}

\section{Resumo}

Desde o início da humanidade até a modernidade e pós-modernidade, os fatores determinantes e condicionantes relacionados às questões ambientais têm causado impactos sobre a saúde em geral e, em particular, sobre a saúde reprodutiva. Os objetivos foram: a) identificar a presença dos temas saúde reprodutiva e meio ambiente na mídia impressa - jornais; b) entender as condições de produção circulação e recepção das reportagens. Utilizou-se a metodologia qualitativa, com as figuras metodológicas que constituem o Discurso do Sujeito Coletivo. Selecionou-se 30 reportagens no período de janeiro de 2007 a abril de 2008. Conclui-se que o DSC, proporcionou maior aproximação com os múltiplos discursos sobre saúde reprodutiva e meio ambiente. Esta análise foi rica, do ponto de vista do material analisado e, complexa do ponto de vista das relações de poder, da hegemonia e da ideologia presentes nos discursos.

Palavras-chaves: Discurso, Saúde reprodutiva, Meio ambiente.

\begin{abstract}
Since the beginning of humanity to modernity and post-modernity, the determining factors and conditions related to environmental issues have caused impacts on health in general and especially on reproductive health. The objectives were: a) identify the presence of issues on reproductive health and environment in the printed media newspapers; b) understand the conditions of production, circulation and receipt of reports. The method was the qualitative, with the methodological figures which constitute the Discourse of the Collective Subject.- Thirty reports were selected, between January 2007 and April 2008. It was concluded that the DCS, offers a greater approach with the numerous speeches about reproductive health and environment. This analysis was rich in terms of the material analyzed and complex in terms of power relations, hegemony and ideology in the dicourses.
\end{abstract}

Key words: Discourse, Reproductive health, Environment. 


\section{Introdução}

Desde o início da humanidade até a modernidade e pós-modernidade, os fatores determinantes e condicionantes relacionados às questões ambientais têm causado impactos sobre a saúde em geral e, em particular, sobre a saúde reprodutiva.

No contexto deste texto, focaremos os discursos sobre saúde reprodutiva e meio ambiente, presentes na mídia impressa, com ênfase especial sobre saúde reprodutiva, direitos reprodutivos, direitos sexuais e saúde sexual.

Saúde reprodutiva é um tema amplamente debatido em diversos eventos científicos, como por exemplo, a Conferência Internacional sobre População e Desenvolvimento - CIPD, realizada em 1994 no Cairo/Egito. O conceito de saúde reprodutiva pauta-se no entendimento de estado de bem-estar, que permite às pessoas terem a capacidade de reproduzir-se e de regular sua fecundidade (HARDY, 1998).

A articulação entre saúde reprodutiva e direitos reprodutivos implica formulações discursivas de outra natureza, que evoluíram no Brasil a partir de muitos discursos institucionais. Para exemplificar, os discursos sobre direitos reprodutivos reduzem-se a acesso da pessoa em idade reprodutiva aos serviços de saúde reprodutiva (CORRÊA, 1999).

Entretanto, a expressão saúde reprodutiva incorpora a capacidade de a pessoa decidir e regular sua fecundidade, no momento que lhe é mais oportuno, independente de sua vida sexual. Vida sexual não é sinônimo de vida reprodutiva. A pessoa tem direito a uma vida sexual ativa e uma vida reprodutiva saudáveis como cidadão e cidadã de direitos.

$\mathrm{Na}$ perspectiva feminista adotada por Ávila (2003), os direitos reprodutivos dizem respeito à igualdade e liberdade na esfera da vida reprodutiva e os direitos sexuais no exercício da sexualidade, ou seja, devem ser tratados no âmbito da cidadania e da vida democrática. A autora considera importante tratar esses direitos no sentido de liberdade e igualdade, e não no sentido prescritivo de constituição de um modelo de regras e valores.

Nesse contexto, o conceito de saúde reprodutiva surge como o conjunto mínimo de condições que garantam às mulheres a procriação ou não e que estas escolhas não se constituam em risco de vida ou em danos à sua saúde (VILLELA, 2008).

Esse conceito busca romper com a idéia de reprodução como um dever ou como destino feminino. Situa-se como um direito humano básico que deve ser garantido por Estados e Governos. 
No que concerne ao meio ambiente, é preciso relacionar o possível efeito da degradação ambiental sobre a saúde das pessoas, incluindo aí a sexual e reprodutiva.

Ao contrário do que coloca Hogan (2007), esta percepção não emerge tão claramente para os cientistas e para as instituições públicas de saúde. Mesmo relacionando as áreas de saúde e ambiente, estes ainda têm inúmeras dificuldades políticas, financeiras, institucionais, socioculturais e históricas - para lidar com essas questões, de forma a minimizar os impactos negativos da ameaça à saúde que a poluição da água, do ar e do solo causa aos seres humanos e a outros seres vivos.

Os aspectos relacionados à saúde e ao ambiente também têm um outro lado da moeda que precisa ser desvendado. Os governos, principalmente de países em desenvolvimento, incentivam o controle da natalidade e fertilidade e apóiam a diminuição do número de filhos, como é o caso da China.

Revistas especializadas, documentos legais, programas governamentais, mídia impressa e televisiva divulgam inúmeras informações sobre vários temas pertinentes à saúde reprodutiva.

As informações divulgadas pelos jornais sobre os temas saúde reprodutiva e meio ambiente tratam de questões fundamentais relacionadas à vida humana e à qualidade de vida. As informações são, comumente, veiculadas de forma sensacionalista ou mesmo, superficiais. Sensacionalista porque a mídia precisa chamar a atenção para assuntos que mobilizam o público em suas dimensões afetivas e emocionais.

Desse modo, a informação não tem caráter de divulgação do conhecimento. A mídia não se responsabiliza pela formação de opiniões, e poucas se importam como essas informações geram impacto na população geral a partir do que é veiculado.

Por vezes, as notícias deixam a desejar, podendo confundir, mais do que esclarecer os seus leitores. A mídia, em vez de informar, pode causar enormes dificuldades no processo de apreensão e compreensão dos avanços científicos e tecnológicos por parte da sociedade.

A problemática aqui exposta aponta para a necessidade de uma discussão e reflexão mais aprofundada entre especialistas da área, sociedade civil, instituições governamentais e não-governamentais.

A forma de atuação de alguns países latino-americanos, incluindo o Brasil, é por vezes vertical. A adoção de medidas de controle de natalidade como forma de limitar o nascimento de filhos, e conseqüentemente conter a explosão populacional. 
A falta de planejamento educacional que proporcione a compreensão dos problemas relacionados a degradação do meio ambiente, por exemplo, reduz a problemática da fertilidade a concepção ambiental, de acesso a alimentos, de superpovoamento das áreas urbanas e desocupação das áreas rurais.

Essa visão reducionista impede a apropriação social do conhecimento, até mesmo pela dificuldade de acesso às informações sobre os temas e impossibilidade de um debate mais amplo entre os atores envolvidos.

Ainda sob esse ponto de vista, podemos dizer que, além das questões de saúde pública, os aspectos da promoção e educação em saúde devem ser levados em consideração porque, quando se trata de saúde reprodutiva e meio ambiente, muitos de seus conflitos e dilemas podem ser minimizados em relação à promoção e educação em saúde.

De acordo com o acima exposto, os objetivos deste trabalho de pesquisa são:

a) identificar a presença dos temas saúde reprodutiva e meio ambiente na mídia impressa - jornal de grande circulação e;

b) entender as condições de produção circulação e recepção das reportagens.

\section{Materiais e Métodos}

Neste trabalho, o estudo baseou-se em metodologia qualitativa, cujas principais características são descritas a seguir: a) o objeto das ciências sociais é histórico; b) o objeto de estudo das ciências sociais é a consciência histórica; c) existe uma identidade entre sujeito e objeto; d) ela é intrínseca e extrinsecamente ideológica e; e) ela é essencialmente qualitativa.

As pesquisas baseadas nas ciências sociais abordam o conjunto das expressões humanas constantes nas estruturas, nos processos, nos sujeitos, nos significados e nas representações (MINAYO, 2003).

Foram selecionadas 30 reportagens nos jornais Folha de São Paulo/SP e O Globo/RJ, no período de janeiro de 2007 a abril de 2008. Essas reportagens foram identificadas e selecionadas a partir dos temas saúde reprodutiva e meio ambiente de acordo com as figuras metodológicas que constituem o Discurso do Sujeito Coletivo (DSC). Essas figuras são formadas por expressões-chave, idéias centrais, ancoragem e a síntese das figuras, por eles denominados de discurso do sujeito coletivo.

Esse método de análise privilegia os pensamentos, crenças, opiniões, percepções, valores etc. através da matéria discursiva presente em determinado texto, 
obtidos por meio de artigos de jornais, depoimentos, matérias de revistas, cartas, revistas especializadas e outros materiais textuais (LEFÈVRE e LEFÈVRE, 2003).

\section{Expressões-chave}

As Expressões-chave (ECH) são pedaços, fragmentos, trechos ou transcrições literais do discurso que compõem a totalidade de um texto. A literalidade do depoimento é fundamental para que o leitor analise as condições do contexto em que foi escrito. Erros ortográficos, falta de acentuação, silêncios, jargões, gíria e outros desvios da linguagem culta não podem ser considerados nas ECH porque qualquer alteração poderia prejudicar a análise do leitor do ponto de vista da fidedignidade e do contexto no qual se produziu o discurso textual.

De acordo com Lefèvre e Lefèvre (2003), as ECH equivalem a um tipo de prova discursivo-empírica que corrobora as idéias centrais e as ancoragens. "É através desta matéria-prima das expressões-chave que se constroem os Discursos do Sujeito Coletivo" (p.17).

\section{Idéias Centrais}

A idéia central (IC) é um nome ou expressão lingüística que revela e descreve, de maneira sucinta, o sentido de cada discurso textual. Ela deve ser coerente com o texto em geral e não apenas com a expressão-chave que foi ou está para ser selecionada. Como exemplo do trabalho em questão, as idéias centrais coincidiram, na maioria das vezes, com o título das reportagens selecionadas. Já, em um depoimento, essa figura metodológica pode ser identificada através das expressões-chave ou em outra parte do texto. Elas são descritas de forma sucinta pelo pesquisador para melhor compreensão do que o sujeito enunciador está falando.

\section{Ancoragem}

Algumas expressões-chave podem remeter à figura metodológica da ancoragem (AC) por se inspirarem na teoria da representação social. Essa representação em forma de discurso textual expressa explicitamente a teoria, crença, ideologia que o autor do discurso professa e que está sendo utilizada para determinar uma situação específica.

O leitor pode identificar no texto a ancoragem que aquele discurso pretende professar, depois de repetidas leituras ou imediatamente, dependendo de sua inserção no 
texto e de acordo com suas crenças, valores, sentimentos, percepções e motivações práticas. Quando se deseja realizar atividades educativas com a população ou com profissionais, essa figura metodológica é essencial para tornar manifestas as teorias, ideologias e conceitos que permeiam os discursos e que estão implícitos nas práticas cotidianas e profissionais.

A aplicação dessa figura metodológica do DSC não foi identificada nas reportagens, objeto de análise do presente estudo. De acordo com Lefèvre e Lefèvre (2003, p. 50), isso pode acontecer sempre que a figura não se apresentar de forma concreta e explicita no discurso.

\section{Discurso do Sujeito Coletivo}

Após a identificação, seleção e transcrição das expressões-chave (ECH), idéias centrais (IC) e/ou ancoragens (AC), dá-se início a elaboração do discurso do sujeito coletivo (DSC) que é a síntese das figuras metodológicas anteriormente citadas.

Os discursos não se anulam ou se reduzem a uma determinada categoria aglutinadora, ao contrário, são realizados quantos discursos forem necessários para expressar um determinado contexto ou uma representação social sobre um determinado fenômeno.

Através da identificação, seleção e elaboração das figuras metodológicas anteriores, chega-se ao DSC por meio destas, tendo a possibilidade de visualizar melhor a representação social daquele contexto na medida em que esta aparece, sob a forma de um discurso, e expressa o pensamento das pessoas sobre uma situação real e concreta.

Descrevemos a seguir o caminho que foi percorrido desde a seleção das reportagens até a elaboração do painel elaborado com os DSC.

O material discursivo obtido através dos textos é analisado extraindo-se de cada um as idéias centrais (IC) e/ou ancoragens (AC) e suas correspondentes expressõeschave (ECH). Para tanto, é necessário leitura e releitura de todo o material, um por um, detalhadamente, para que as figuras metodológicas que compõem o Discurso do Sujeito Coletivo (DSC) possam ser identificadas e transcritas em forma de quadro, painel, itens ou de outra forma que o leitor dos discursos queira realizar.

Iniciamos o trabalho com a seleção e organização das reportagens pela data em que foram publicadas. Cada reportagem foi lida pelo menos duas vezes. Na primeira leitura, era identificada a idéia central (IC) e transcrita para o painel que será apresentado nos resultados e discussões. Na segunda leitura, a partir das (IC) 
identificamos as expressões-chave (ECH) e digitamos à esquerda das (IC) no painel. Por último, realizamos uma última leitura para identificar as ancoragens de cada discurso e digitá-las à direita das idéias centrais (IC). Constituímos assim um painel no qual foram digitadas as expressões-chave (ECH), idéias centrais (IC) e ancoragens (AC). No item abaixo, que trata dos resultados e discussão, serão apresentados o painel e a síntese dos discursos do sujeito coletivo (DSC).

\section{Resultados}

As reportagens foram escolhidas a partir dos temas saúde reprodutiva e meio ambiente. Abaixo, elaboramos um quadro de acordo com o número de reportagens selecionadas e os cadernos onde elas foram publicadas.

Quadro 1. Quantidade de reportagens sobre saúde reprodutiva e meio ambiente. Jornal Folha de São Paulo/SP e O Globo/RJ, segundo cadernos de publicação. 2007-2008.

\begin{tabular}{|l|l|l|l|}
\hline Jornaislcadernos & O Globo & $\begin{array}{l}\text { Folha de São } \\
\text { Paulo }\end{array}$ & Total \\
\hline Brasil/saúde & 01 & & $\mathbf{0 1}$ \\
\hline Ciência/saúde & 12 & & $\mathbf{1 2}$ \\
\hline Cotidiano & & 03 & $\mathbf{0 3}$ \\
\hline Equilíbrio & & 02 & $\mathbf{0 2}$ \\
\hline Ilustrada & & 01 & $\mathbf{0 1}$ \\
\hline Mundo & 03 & & $\mathbf{0 3}$ \\
\hline Opinião & & 04 & $\mathbf{0 4}$ \\
\hline Painel do Leitor & & 01 & $\mathbf{0 1}$ \\
\hline Política & 01 & & $\mathbf{0 1}$ \\
\hline Tendências/debates & 02 & & $\mathbf{0 2}$ \\
\hline TOTAL & $\mathbf{1 9}$ & $\mathbf{1 1}$ & $\mathbf{3 0}$ \\
\hline
\end{tabular}

Fonte: Jornais - Folha de São Paulo e O Globo, janeiro de 2007 a abril de 2008.

Não se deve relegar também a importante participação da sociedade civil organizada para o debate público e efetivo nas decisões e deliberações sobre os temas das reportagens que constituíram os Discursos dos Sujeitos Coletivos - DSC. As 
participações foram identificadas nos cadernos Painel do Leitor e Opinião do jornal Folha de São Paulo e no caderno Tendências/Debate do jornal O Globo.

Os temas saúde reprodutiva e meio ambiente foram retratados por diferentes cadernos dos dois jornais, totalizando 30 reportagens. O quadro anterior apresenta a distribuição dessas reportagens, da forma pela qual elas são alocadas pelos cadernos dos jornais pesquisados. A seguir, descrevemos os resultados obtidos com a análise do DSC.

O trabalho realizado com a estratégia metodológica do Discurso do Sujeito Coletivo tornou possível evidenciar e compreender, através das reportagens, as relações entre saúde reprodutiva e meio ambiente. Os depoimentos dos jornais permitiram levantar indícios concretos sobre a possibilidade de produção e reprodução dos temas.

\section{DSC das reportagens publicadas sobre o uso de métodos contraceptivos}

\section{Expressões-chave:}

"Escolas públicas que desenvolvem programas de prevenção e de saúde reprodutiva ganharão equipamento de distribuição de camisinhas".

“O Ministério da Saúde pretende distribuir gratuitamente, em 2007, cerca de 200 mil cartelas das "pílulas do dia seguinte" como são conhecidas as cápsulas de anticoncepcionais que podem ser usadas depois das relações sexuais realizadas sem proteção. O governo federal investiu 115 milhões na compra dos medicamentos, que são entregues nos postos de saúde e hospitais de 1.300 cidades do país".

Idéia central: a prevenção como mera distribuição de anticoncepcionais.

\section{DSC das reportagens publicadas sobre fertilidade}

\section{Expressões-chave:}

"Se havia uma área em que os homens pareciam invulneráveis era na capacidade reprodutiva [...] Isto está caindo por terra [...] E a causa seria o envelhecimento da fábrica de espermatozóides, os testículos [...] "O testículo é mais frágil do que o ovário, porque está mais exposto a agressões ambientais, com conseqüências danosas aos espermatozóides".

"Cientistas preparam o primeiro transplante de útero de uma mulher nos Estados Unidos, informa o jornal americano "The Washington Post" [...] Porém, os riscos para as mulheres e para um futuro feto aumentaram a preocupação de alguns médicos e cientistas, que consideram que um procedimento de transplante uterino ainda não foi 
suficientemente testado em animais como para ser realizado em humanos, afirma o "Post".

"Numa decisão inédita, a justiça canadense autorizou uma mulher a doar óvulos para sua própria filha, uma menina de sete anos que é portadora da síndrome de Turner, doença genética que a torna infértil. $\mathrm{O}$ aumento dos níveis de obesidade entre a população dos países ocidentais terá como consequiência um aumento nos casos de infertilidade feminina, adverte um estudo realizado por cientistas da Austrália e Reino Unido. A advertência foi feita pelos especialistas, que previnem que os níveis de infertilidade nos chamados "países desenvolvidos" aumentarão nos próximos dez anos [...]".

“Os problemas de fertilidade masculina são determinados no útero materno, sugeriu pesquisa da Universidade Edimburgo, na Escócia. Distúrbios genitais comuns como baixa contagem de espermatozóides no esperma e câncer testicular podem ligados a níveis de hormônios nos primeiros estágios da gravidez, concluíram os pesquisadores, depois de realizarem estudos com ratos de laboratório".

"Mulheres que privilegiam a carreira, mas também querem ter filhos, cuidado: não dá para enganar a natureza. Uma análise exaustiva do funcionamento da fertilidade feminina sugere que é extremamente difícil, se não impossível, melhorá-la depois que a mulher chegou a um período crítico que antecede a menopausa em cerca de dez anos [...] O único jeito de contornar o problema é descobrir quais mulheres têm predisposição para a infertilidade precoce e aconselhá-las [...]”.

Idéia central: gênero, fertilidade e infertilidade.

\section{DSC das reportagens publicadas sobre sexualidade e saúde reprodutiva}

\section{Expressões-chave:}

"Os homens que possuem voz grave costumam ter mais filhos [...] "Descobrimos que os homens com voz grave têm mais filhos do que os que têm voz aguda" [...] antropóloga da Universidade de Harvard [...] A associação entre o êxito reprodutivo e o tom de voz nos homens se de provavelmente a seu maior acesso a mulheres fecundas. De acordo com informações anteriores de um artigo publicado on-line para a edição de 22 de dezembro da revista científica "Biology Letters", a maioria das mulheres das sociedades ocidentais se sente mais atraída a homens que têm voz mais grave, associando essa 
característica a indivíduos mais saudáveis e viris. Os homens, por sua vez, acham que as vozes mais agudas são mais atraentes".

Idéia central: sexualidade e saúde reprodutiva.

\section{DSC da reportagem publicada sobre sexualidade e idade reprodutiva} Expressões-chave:

"[...] se via, aos 64 anos, levando uma vida pacata, cercado de netos. Mas uma mulher de origem turca vivendo na Alemanha tinha outros planos. Ela acaba de se tornar a mulher mais velha a dar à luz um filho naquele país [...] A mulher, que não teve sua identidade divulgada, fez uma inseminação artificial fora do país, para onde voltou para ter o bebê - já que o procedimento é proibido na Alemanha [...] Em declaração à BBC, Ulrich Hilland, presidente da Associação Alemã de Medicina Reprodutiva, classificou a gravidez como um "abuso do progresso da medicina".

Idéia central: sexualidade e idade reprodutiva

\section{DSC das reportagens sobre distúrbios femininos e saúde reprodutiva}

Expressões-chave:

"Ficar de cama "naqueles dias" é normal na adolescência [...] alerta nacional para que as famílias desconfiem da recorrência de cólicas incapacitantes: é o primeiro sintoma da endometriose, que pode levar à infertilidade na idade adulta e que tem muito mais chances de ser contornada com um diagnóstico precoce”.

"A chegada de um novo equipamento no país para tratar miomas uterinos engrossa a polêmica sobre qual a melhor terapia para o problema que atrapalha a vida de $30 \%$ das mulheres em idade reprodutiva, que sofrem com fortes cólicas e sangramentos. $\mathrm{O}$ aparelho que associa ressonância magnética a ultra-som, promete inativar o mioma [...] sem corte e sem dor [...] O otimismo em relação ao tratamento com ultra-som não se aplica à grande parte da comunidade médica [...] não há evidências científicas de sua eficácia”.

Idéia central: distúrbios femininos e saúde reprodutiva.

\section{DSC das reportagens sobre aborto}

Expressões-chave:

"As declarações do ministro da Saúde, José Gomes Temporão, na "Entrevista da 2a", apontam para o desafio de discutir saúde reprodutiva em nosso país como questão de 
saúde pública. A nossa sociedade, influenciada pela doutrina cristã, resiste a prática de educar para prevenir e disponibiliza poucos meios para que as pessoas exerçam a sexualidade com autonomia e planejamento reprodutivo. Tratar o aborto apenas como questão moral e criminalizar as mulheres, sem considerar a vulnerabilidade da maioria delas, é injusto e desumano".

“A SUGESTÂO de levar a plebiscito a proposta de descriminalizar o aborto no Brasil ganhou evidência ao receber a adesão do ministro da saúde, José Gomes Temporão [...] De acordo com pesquisa Datafolha [...] 65\% dos brasileiros se opõem a mudanças no "status quo", 16 sustentam que o aborto deve ser permitido em mais situações do que as previstas pela lei atual [...] e apenas $10 \%$ advogam pela descriminalização plena”.

"No Brasil o abortamento inseguro constitui uma das maiores causas de morte de gestantes, mas elas são, [...] "só a ponta de um grande iceberg”, pois centenas de mulheres continuam suportando terríveis consequiências físicas e psíquicas em razão do abortamento realizado em condições precárias e inseguras”.

“[...] Ser a favor da descriminalização do aborto não é ser a favor do aborto [...] é um caminho para controlá-lo, diminuir sua incidência e também as mortes por ele causadas quando provocado em condições inadequadas que fizeram da mortalidade materna em adolescentes, no Brasil, uma das maiores do mundo [...] posso apontar uma série de políticas distorcidas, de equívocos e displicências do poder público que levam criminosamente à tragédia do aborto [...] A falta de educação reprodutiva nas escolas, a deseducação causada pela televisão e a não disponibilização de metodologias anticoncepcionais eficientes nos postos de saúde são algumas delas”.

"DENTRO OU fora da lei, o aborto induzido é uma realidade. No Brasil, estima-se que, a cada ano, até 1 milhão de mulheres interrompam clandestinamente a gravidez [...] Estudo do Centro de Pesquisas em Saúde Reprodutiva de Campinas [...] revela um quadro desolador [...] O panorama tampouco é bom no quesito educação. Faltam campanhas de prevenção da gravidez precoce. Muitos diretores de escola resistem a admitir a temática da educação sexual. Além disso, as UBSs não estão aparelhadas para fornecer esse tipo de informação".

"[...] A quantidade de abortos induzidos no mundo todo caiu entre 1995 e 2003, mas esse número ainda é alto na América Latina, Ásia e na África, segundo um estudo publicado [...] O documento, elaborado pelo Instituto Guttmacher dos Estados Unidos e pela Organização Mundial da Saúde (OMS), mostra que a quantidade de abortos no 
mundo todo passou de 46 milhões, em 1995, para menos de 42 milhões em 2003 [...]" "As novas provas confirmam mais uma vez o que já sabemos: a melhor maneira de evitar um aborto é ajudando as mulheres a evitar uma gravidez indesejada" [...] "E sabemos também que o primeiro passo crucial para fazer com que o aborto seja seguro é legalizar o procedimento, assegurando que seja realizado por pessoas qualificadas e nas melhores condições possíveis".

"A socióloga Dulcelina Vasconcelos Xavier, diretora movimento das Católicas pelo Direito de Decidir e secretária das Jornadas pelo Direito ao Aborto Legal e Seguro, criticou [...] declaração do governador do Rio de Janeiro, Sérgio Cabral (PMDB), que defendeu o aborto para reduzir a violência no Estado. Para Dulcelina, "reduzir a violência não tem nada a ver" com legalização do aborto. "O que gera a violência é a falta de acesso à educação, a falta de políticas públicas para cuidar das crianças. O aborto não é solução para redução da violência, é um perigo grande pensar por esse lado".

"OITO ANOS depois da divulgação do trabalho seminal de Steven Levitt, muito se discute sobre a validade e o uso do seu resultado. O artigo mostra que a decisão da Suprema Corte americana, que permitiu em 1973 o aborto nos 50 Estados daquele país, foi determinante para a forte redução nas taxas de criminalidade na década de 90 . Susan Wicklund passou por aborto traumático na juventude. Agora ela se dedica a tornar a experiência o mais humana possível para outras americanas [...] Wicklund disse que as taxas atuais indicam que $40 \%$ das mulheres americanas fazem um aborto durante a idade em que podem conceber um número que é validado pelo Guttmacher Institute, que pesquisa a política de saúde na área de reprodução humana”.

Idéia central: legalização, descriminalização e criminalização do aborto.

\section{DSC das reportagens sobre poluição ambiental e saúde reprodutiva}

Expressões-chave:

"[...] a genitália dos ursos polares machos parece estar encolhendo, afirmam pesquisadores. A culpa pode ser atribuída a poluentes industriais [...] o problema também pode atingir outros mamíferos do pólo Norte, como raposas-do-ártico e orças. Assim como os ursos polares, esses bichos carregam altíssimos níveis de poluentes em seu organismo".

"Pesquisadores da Universidade de Pisa analisaram 10 mil homens durante 30 anos e verificaram que houve uma diminuição no número de espermatozóides, principalmente 
entre os que viviam em grandes centros urbanos e zonas mais poluídas [...] Essas diminuições não querem dizer que os homens ficaram estéreis, significa que a fertilidade deles corre maiores perigos[...]".

"Defeitos no sêmen causados pela exposição a toxinas presentes no meio ambiente podem ser passados para futuras gerações [...] os pais que bebem e fumam devem estar cientes de que eles estão, potencialmente não apenas prejudicando a si mesmos, mas também seus filhos [...] a pesquisa demonstra que defeitos causados pelas toxinas nos genes permanecem na linha reprodutiva da família, afetando até quatro gerações [...] $\mathrm{O}$ estudo sugere que a saúde do pai tem papel mais importante sobre a saúde das futuras gerações do que se pensava".

Idéia central: Poluição e comprometimento da genitália de mamíferos.

\section{DSC da reportagem sobre taxa de natalidade e crescimento populacional}

Expressões-chave:

"A HUMANIDADE se aproxima de uma crise. Durante todo o tempo de duração de vida de nossos filhos, nosso objetivo deve ser o de atingir crescimento populacional igual a zero". Essa foi a conclusão a que chegaram os participantes da conferência sobre crescimento populacional, patrocinada pela "World's Scientific Academies" [...] dada a importância do relatório e da idoneidade de seus autores, vou resumir suas conclusões. 1) erradicar a fome e a pobreza extrema 2) educação primária universal 3) promover igualdade de gênero e dar mais poder às mulheres 4) reduzir a mortalidade infantil 5) promover a saúde materna 6) Combater a Aids, malária e outras enfermidades 7) Garantir o desenvolvimento sustentável”.

Idéia central: taxa de natalidade e crescimento populacional

\section{DSC da reportagem sobre mortalidade e indicadores de desenvolvimento} Expressões-chave:

"A CADA dia, mais de 1.400 mulheres e adolescentes morrem desnecessariamente por causa de um ato essencialmente natural: dar à luz [...] As complicações da gestação são a principal causa de problemas entre as mulheres jovens no mundo em desenvolvimento [...] Na África, uma mulher corre, ao longo de sua vida, um risco de morte materna de 1 em 26, em comparação com um risco de 1 em 7.300 para as mulheres que vivem em regiões mais desenvolvidas". 
Idéia central: mortalidade e indicadores de desenvolvimento

\section{DSC da reportagem sobre direitos reprodutivos e desenvolvimento sociocultural} Expressões-chave:

“A secretária da Rede Feminista de Saúde [...] participou junto com deputadas européias e representantes de governos e movimentos de esquerda latino-americanos de um encontro em Bruxelas para discutir os direitos femininos. Na reunião, organizado pelo grupo parlamentar de Esquerda Unitária Européia, os participantes alertaram que a América Latina está atrasada em relação aos direitos reprodutivos e sexuais das mulheres".

Idéia central: direitos reprodutivos e desenvolvimento sócio-cultural.

\section{DSC da reportagem sobre menopausa como produto da seleção natural}

Expressões-chave:

"Cientistas britânicos sugeriram que as mulheres entram na menopausa para evitar "competir" em termos reprodutivos com a geração seguinte. Em um ambiente de competitividade e escassez de alimentos, a seleção natural beneficiou as crias da mulher mais nova, fazendo com que as mais velhas perdessem capacidade de procriar, eles afirmam, em um estudo publicado [...] na revista científica Proceedings of the National Academy of Sciences".

Idéia central: menopausa e seleção natural.

\section{DSC da reportagem sobre a influência da alimentação materna na gravidez} Expressões-chave:

"A dependência de "junk food", ou comida lixo, uma das causas principais de obesidade na infância, pode começar no útero materno, segundo um estudo publicado no "British Journal of Nutrition” [...] Segundo os cientistas, as mães que comem alimentos pouco saudáveis enquanto amamentam também podem influir negativamente no peso de seus filhos".

Idéia central: alimentação da mãe durante e peso dos filhos.

\section{A discussão dos dados}

Condensamos os diferentes depoimentos e a partir daí elaboramos os discursos dos sujeitos coletivos (DSC), que significam discursos-síntese. 
Cada um dos episódios acima relacionados expressa a manifestação das vozes dos vários autores do discurso (BAKHTIN, 2003), que se configuram como os produtores das reportagens.

O discurso escrito, entendido aqui como as reportagens, é parte integrante de uma discussão ideológica maior, na qual responde a alguma coisa, refuta, confirma, procura apoio (BAKHTIN, 2004, p. 123), divulga e informa.

A inter-relação das leituras das reportagens e a heterogeneidade dos discursos sobre saúde reprodutiva e meio ambiente produziram material rico em detalhes e diversidade na compreensão dessas áreas.

A análise do material obtido através das idéias centrais sobre métodos contraceptivos, fertilidade e infertilidade, sexualidade, distúrbios femininos, aborto, poluição ambiental, taxa de natalidade e crescimento populacional, mortalidade materna e indicadores de desenvolvimento, direitos reprodutivos e desenvolvimento sociocultural, menopausa como produto da seleção natural, alimentação na gravidez proporcionou essa riqueza.

As relações dialógicas entre os discursos, aqui apresentadas, refletem o contexto sócio-histórico em que estão inseridos e são concebidos como um tecido de muitas vozes que se entrecruzam, se completam, respondem umas às outras, polemizam entre si no interior dos textos e possuem um caráter ideológico (BARROS, 2005).

A formação discursiva das reportagens nos remete à importância da saúde reprodutiva como área do conhecimento e como questão de saúde pública, que deve ser discutida não apenas em fóruns acadêmicos, institucionais e religiosos, mas também, na sociedade civil de forma organizada e efetiva. Nesse sentido, os discursos aqui apresentados, sobre os direitos à saúde devem ser entendidos também, como direito à cidadania.

Como se pode constatar pelo número de exemplos que trouxemos acerca do tema do aborto, este foi bastante recorrente. O Discurso do Sujeito Coletivo - DSC referente a essas reportagens sobre o aborto corroboram a necessidade de participação da sociedade civil na discussão desta questão fundamental.

Dessa forma, acreditamos ser possível legitimar as deliberações acerca de um tema tão complexo como o aborto, que envolve outros aspectos que vão além do ato de suspensão de uma gravidez indesejada. 
Vale ressaltar que foram quatro os artigos em cadernos que são dedicados ao debate sobre as motivações e os limites das práticas abortivas, indicando os desdobramentos nem sempre observadas por especialistas do campo da saúde reprodutiva.

Ainda sob este aspecto, é interessante destacar que as mulheres vêm participando e influindo cada vez mais no debate sobre o aborto, pois as ações de organizações não-governamentais de mulheres no debate público influenciaram e ainda influencia a formulação de políticas e as reformas legais, abrindo assim espaço para o envolvimento positivo com a mídia.

Neste aspecto, ela não é só um instrumento poderoso de produção, circulação e consumo de conteúdos simbólicos, ela tem um poder transformador imenso, que ainda é pouco estudado (LYRA e MEDRADO, 1999). A linguagem midiática faz parte do contexto contemporâneo e a sua utilização deve ser uma estratégia de transformação social (p.18).

As reportagens sobre fertilidade e infertilidade foram marcadas pelo caráter reprodutivo em sua dimensão biológica e dependente de variações hormonais e função do órgão reprodutor. Entretanto, não foram enfatizadas as questões sociais e afetivas inerentes à necessidade humana de perpetuar a sua espécie e de constituir família com um direito humano fundamental. A redução da problemática da fertilidade a dimensão ideológica biologicista impede a apropriação de informações de maior amplitude que estimule a reflexão humana.

Estudos relacionando fisiologia da reprodução e ecotoxicologia (meio ambiente) identificaram agentes químicos mutagênicos e teratogênicos; sem, no entanto, avaliar as conseqüências destes sobre a fecundidade (HOGAN, 2007). Quanto à relação meio ambiente e morbidade/mortalidade, temos, na epidemiologia, os maiores estudos sobre as conseqüências da poluição ambiental sobre aqueles. Existe a preocupação de estabelecer nexos causais, relações e significância estatística.

A análise dos aspectos de fecundidade, morbi/mortalidade passa pela saúde (HOGAN, 2007). Além destes, devemos levar em conta os aspectos de migração, fome e desnutrição, degradação e poluição ambiental, educação e promoção da saúde. Os impactos sobre a saúde das pessoas são crescentes, na medida em que a Medicina e outras áreas do conhecimento ignoram as doenças antigas e o aumento do poder do homem sobre a natureza. 
Nesse contexto, o saber acadêmico pode associar e produzir formas criativas de inovação científica e tecnológica, e reivindicar formas mais dinâmicas de contrato social. Desse modo, atender às necessidades e anseios, por mínimos que sejam, às idéias, opiniões, pensamentos, crenças, valores, percepções, conhecimentos, que podem oferecer ao outro e a nós mesmos a oportunidade de reafirmação enquanto sujeitos históricos e cidadãos críticos (COSTA et. al., 2007).

\section{Considerações finais:}

Os temas saúde reprodutiva e meio ambiente, mais abordados na mídia impressa foram fertilidade, aborto, contaminação ambiental e diminuição da genitália, métodos contraceptivos, mortalidade materna, menopausa, distúrbios femininos, entre outros.

A heterogeneidade dos discursos manifestou-se pelas diferentes vozes e interesses presentes nas reportagens e indica a preocupação de seus autores das mesmas com os temas que foram identificados nas expressões-chave e nas idéias-centrais.

Porém, essa polissemia deve ser valorizada de acordo com o debate e a participação efetiva do público a que se destinam essas reportagens. Nesse contexto, o espaço para isso são os locais onde o leitor possa dialogar com o autor das reportagens e talvez com outros leitores, como por exemplo, os cadernos Painel do Leitor, Opinião e Tendências e Debates.

Em relação à escrita deste artigo, entendemos que as condições de produção, circulação e recepção das reportagens possuem caráter sócio-histórico e podem atender a determinados interesses. Neste sentido, a mídia impressa insere-se no contexto de mercado, no qual sua sobrevivência depende das vendas dos jornais e de seus índices.

É interessante refletir sobre isso porque os eventos que têm a possibilidade de virar notícia podem ser originados por um grupo seleto de pessoas que têm acesso privilegiado à mídia e que são tratados por profissionais da mídia impressa como fontes confiáveis e suas vozes são freqüentemente representadas no discurso midíatico.

O discurso do sujeito coletivo, inspirado na teoria da representação social, proporcionou, neste trabalho, maior aproximação com os múltiplos discursos sobre saúde reprodutiva e meio ambiente que circulam nas reportagens de jornais. A análise destes discursos é sempre rica do ponto de vista do material a ser analisado e complexo do ponto de vista das relações de poder, da hegemonia e da ideologia presentes nos discursos. 


\section{Referências}

ÁVILA, M. B. Direitos sexuais e reprodutivos: desafios para as políticas de saúde. Cad. Saúde Pública, Rio de Janeiro, v.19, supl.2, p.465-469, 2003.

BAKHTIN, M.M. Estética da Criação Verbal. São Paulo: Martins Fontes, 2003.

BAKHTIN, M.M. (Volochinov). Marxismo e Filosofia da Linguagem. $11^{\text {a }}$ ed. São Paulo: Hucitec, 2004.

BARROS, D.L. P.Contribuições de Bakhtin às Teorias do Discurso. In: Bakhtin, dialogismo e construção do sentido. Brait, B. (org.) $2^{a}$ ed. rev. Campinas-SP: Unicamp; 2005.

BRAIT, B. Bakhtin, dialogismo e construção do sentido. $2^{\text {a }}$ ed. rev. Campinas, SP: Unicamp, 2005.

CORRÊA, S. A Evolução dos Conceitos de Saúde Reprodutiva e Direitos Reprodutivos no Brasil. In: MAcARTHUR - The John D. and Catherine T. MacArthur Foundation. Perspectivas em Saúde e Direitos Reprodutivos, 1999.

COSTA, M.A.; BARBOSA-LIMA, M.C.A.; SOUSA, I.C.F. de; FONSECA, S.N. O diálogo como instrumento de percepção dos problemas. Saneamento Ambiental; 17:125, p.40-44, jan-fev 2007.

HARDY, E. E. Editorial. Saúde reprodutiva na América Latina. Cad. Saúde Pública, Rio de Janeiro, v. 14, suppl. 1, 1998.

HOGAN, D.J. População e Meio Ambiente: a emergência de um novo campo de estudos. In: Dinâmica populacional e mudança ambiental: cenários para o desenvolvimento brasileiro. Daniel Joseph Hogan (Org.). - Campinas: Núcleo de Estudos de População-Nepo/Unicamp, 2007.

LEFÉVRE, F. e LEFÈVRE, A. M.C. Discurso do Sujeito Coletivo: um novo enfoque em pesquisa qualitativa (desdobramentos). Ed. rev. e ampl. Caxias do Sul, RS: Educs, 2003.

LYRA, J.; MEDRADO, B. Mídia como parceira no processo de intervenção social. In: MAcARTHUR - The John D. and Catherine T. MacArthur Foundation. Perspectivas em Saúde e Direitos Reprodutivos, 1999.

MINAYO, M.C.S. (Org.) Deslandes SF, Cruz Neto O, Gomes R. Pesquisa Social: teoria, método e criatividade. 22.ed. Petrópolis: Vozes; 2003.

VILELLA, W. Saúde integral, reprodutiva e sexual da mulher: redefinindo o objeto de trabalho a partir do conceito de gênero e da Conferência Internacional sobre População e Desenvolvimento [on line]. Disponível em:

http://www.mulheres.org.br/documentos/saude_integral.pdf. Acesso em: 14/11/2008. 